\title{
Flora da região de Xingó, Alagoas-Sergipe: Portulacaceae sensu lato
}

\author{
Hermes de Oliveira Machado-Filho ${ }^{1,2 *}$ \\ José Iranildo Miranda de Melo ${ }^{2}$ \\ Margareth Ferreira de Sales ${ }^{3}$ \\ ${ }^{1}$ Instituto Federal de Educação, Ciência e Tecnologia da Paraíba \\ CEP 58015-530, João Pessoa - PB, Brasil \\ ${ }^{2}$ Universidade Estadual da Paraíba, PPG em Ecologia \& Conservação \\ CEP 58429-500, Campina Grande - PB, Brasil \\ ${ }^{3}$ Universidade Federal Rural de Pernambuco, Recife - PE \\ * Autor para correspondência \\ hermes@ifpb.edu.br
}

Submetido em 29/03/2012

Aceito para publicação em 29/08/2012

\section{Resumo}

Portulacaceae Juss. inclui plantas herbáceas a subarbustivas, portando folhas carnosas, alternas, subopostas a opostas, flores bissexuadas, actinomorfas, com ou sem brácteas, e fruto geralmente em cápsula de deiscência longitudinal ou transversal. Este trabalho trata do estudo florístico-taxonômico de Portulacaceae na região de Xingó, nos estados de Alagoas e Sergipe (Nordeste do Brasil). Foram registrados dois gêneros e seis espécies: Portulaca L., com quatro espécies (P. elatior Mart. ex Rohrb., P. halimoides L., P. mucronata Link e P. oleracea L.) e Talinum Adans., com duas espécies (T. paniculatum (Jacq.) Gaertn. e T. triangulare (Jacq.) Willd.). São apresentadas descrições, ilustrações e chaves para separação de gêneros e espécies, além de dados de distribuição e hábitat sobre as espécies encontradas na área.

Palavras-chave: Caatinga; Florística; Taxonomia

\section{Abstract}

Flora of the Xingo region, Alagoas-Sergipe: Portulacaceae sensu lato. Portulacaceae Juss. includes herbaceous to subshrub plants, presenting fleshy leaves, alternate, sub-opposite to opposite, bisexual flowers, actinomorphic, with or without bracts, and fruit usually in capsule with longitudinal or transverse dehiscence. This paper deals with the floristic-taxonomic study of Portulacaceae in the Xingo region, in the states of Alagoas and Sergipe (Northeastern Brazil). We recorded 2 genera and 6 species: Portulaca L., with 4 species (P. elatior Mart. ex Rohrb., P. halimoides L., P. mucronata Link, and P. oleracea L.) and Talinum Adans., with 2 species (T. paniculatum (Jacq.) Gaertn. and T. triangulare (Jacq.) Willd.). We present descriptions, illustrations, and keys for separation of genera and species, besides distribution and habitat data on the species found in the area.

Key words: Caatinga; Floristics; Taxonomy 


\section{Introdução}

Portulacaceae Juss. sensu lato reúne plantas herbáceas, raramente arbustivas ou arbóreas, geralmente suculentas, de folhas simples, alternas, sub-opostas, verticiladas, inflorescências cimosas ou apresentando flores solitárias. Suas flores são bissexuadas raramente unissexuadas, actinomorfas, monoclamídeas (geralmente com um par de bractéolas).

A família pertence à Ordem Caryophyllales, núcleo das Eudicotiledôneas tricolpadas. As relações filogenéticas em Portulacaceae ainda permanecem incertas. As dúvidas consistem principalmente sobre o monofiletismo da família e relações com as famílias Basellaceae e Cactaceae (JUDD et al., 2009), bem como com a família Didieraceae (NYANANYO; MENSSAH, 2004), além da possível ancestralidade com a família Aizoaceae na separação do antigo supercontinente Gondwana (NYANANYO; MENSSAH, 2004).

Recentemente, Nyffeler e Eggli (2010) propuseram uma nova classificação para as plantas suculentas incluindo aproximadamente 12.500 espécies distribuídas em 83 famílias e 690 gêneros. Dentre essas famílias, Portulacaceae encontra-se segregada e o gênero Talinum Adans. está posicionado na família Talinaceae.

Admitindo-se o conceito tradicional de Portulacaceae, a família apresenta distribuição cosmopolita, incluindo cerca de 30 gêneros e 500 espécies. Para o Brasil, foram registrados dois gêneros, Portulaca L. e Talinum Adans., representados por 13 e duas espécies respectivamente (COELHO, 2012) e a região nordeste destaca-se por englobar a maioria dos representantes da família. Apesar disto, estudos enfocando a taxonomia de Portulacaceae sensu lato ainda são incipientes. Para a flora brasileira, os trabalhos sobre esta família foram realizados por Lima e Lima (1968), Rodrigues e Furlan (2002) e Coelho e Giulietti $(2006 ; 2010)$, além da lista elaborada por Coelho (2012).

O presente trabalho consiste do levantamento florístico-taxonômico de Portulacaceae s.l. para a região de Xingó, nos estados de Alagoas e Sergipe, visando contribuir para o conhecimento sobre a riqueza e distribuição da família na flora local e no semiárido brasileiro.

\section{Material e Métodos}

\section{Área de estudo}

A região de Xingó está situada no Nordeste brasileiro entre as coordenadas de $09^{\circ} 30^{\prime}$ a $10^{\circ} 00^{\prime} \mathrm{S}$ e $37^{\circ} 30^{\prime} \mathrm{S}$ a $38^{\circ} 00^{\prime} \mathrm{W}$, envolvendo parte dos estados de Pernambuco, Bahia, Alagoas e Sergipe, no entanto, o presente trabalho inclui apenas o trecho localizado em Alagoas e Sergipe. Possui vegetação tipo Savana Estépica (caatinga), e suas variações (VELOSO et al., 1992), com composição florística ainda pouco conhecida (Figura 1: A-B). O clima da região é do tipo Bshw, quente e seco (KÖEPPEN, 1948), com temperatura média anual variando entre $25^{\circ} \mathrm{C}$ a $27^{\circ} \mathrm{C}$, e precipitação oscilando entre $600-700 \mathrm{~mm}$. Apresenta solos variados, sendo ainda verificada a presença de chapadões areníticos (RADAMBRASIL, 1983).

FIGURA 1: A-B. Feições da área de estudo, Xingó (AlagoasSergipe, Nordeste do Brasil). C. Portulaca elatior Mart. D. P. halimoides L. E. Talinum paniculatum (Jacq.) Gaertn. F. T. triangulare (Jacq.) Willd.
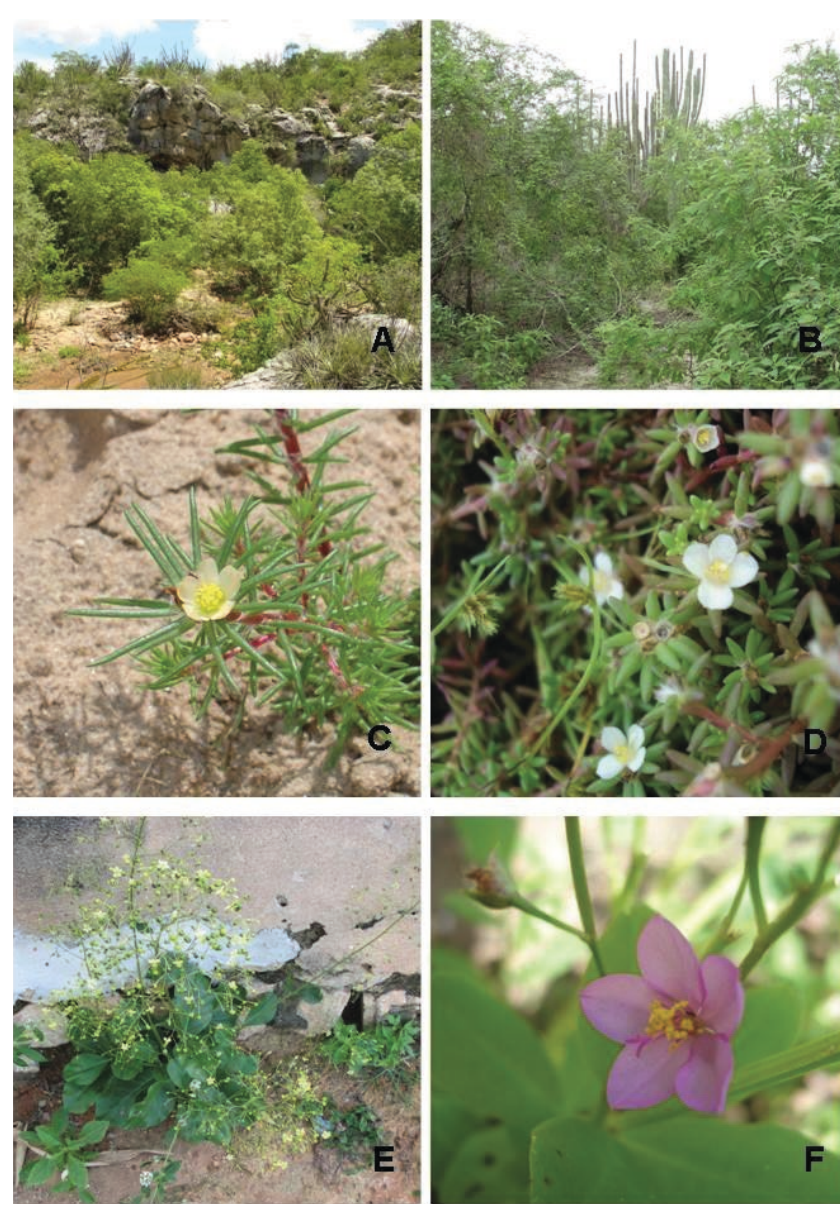


\section{Coleta e tratamento dos dados}

Os materiais foram coletados entre o período de 1999 a 2001 nos Estados de Alagoas e Sergipe, com base no Programa Xingó (CNPq/CHESF), nas áreas de influência da barragem da hidrohelétrica de Xingó (CHESF), e em trechos de caatinga ameaçadas pelo processo de ocupação urbana. O processo de herborização foi baseado nas recomendações de Judd et al. (2009), e as amostras foram incorporadas ao acervo do herbário da Universidade Federal Rural de Pernambuco (PEUFR) e da Universidade Federal de Pernambuco (UFP). A identificação e a terminologia adotada na descrição dos táxons foram baseadas na literatura especializada mencionada na introdução deste trabalho.

Foram confeccionadas descrições, chaves para separação de gêneros e espécies e ilustrações, além de estampas do hábito das espécies. Também são apresentados dados de distribuição geográfica e ambientes preferenciais para as espécies registradas nesse estudo.

\section{Resultados e Discussão}

Foram reconhecidos seis espécies e dois gêneros de Portulacaceae s.l. para a área estudada: Portulaca L., com quatro espécies ( $P$. elatior Mart. ex Rohrb., P. halimoides L., P. mucronata Link e $P$. oleracea L.) e Talinum Adans., com duas (T. paniculatum (Jacq.) Gaertn. e T. triangulare (Jacq.) Willd.).

Portulacaceae Juss., Gen. P1.: 312. 1789.

Ervas anuais ou perenes, simples ou ramificadas, prostradas ou eretas. Folhas simples, opostas ou alternas, com ou sem estípulas, em geral suculentas. Inflorescências em racemo ou cimeira, terminais ou axilares, ou flores solitárias, com ou sem brácteas. Flores actinomorfas, pediceladas ou sésseis; sépalas-2 (raramente 5-9); pétalas 5-18; estame 1-vários; ovário súpero (Talinum) ou ínfero (Portulaca), 1-vários carpelos fundidos, 1-locular; placentação basal ou livre-central. Fruto cápsula loculicida ou pixídio, 1-locular; 2-3 valvas ou opercular; sementes lisas ou esculturadas.
Chave de identificação para os gêneros de Portulacaceae de Xingó (Alagoas e Sergipe):

1. Ovário ínfero; fruto pixídio Portulaca

1. Ovário súpero; fruto cápsula loculicida....... Talinum

Chave de identificação para as espécies de Portulaca de Xingó (Alagoas e Sergipe):

1. Caule prostrado; lâmina foliar linear a oblonga; axilas nodais densamente lanosas P. halimoides

1. Caule ereto a semiprostrado; lâmina foliar linear, lanceolada ou espatulada; axilas nodais glabras a esparsamente pilosas

2. Ervas semiprostradas P. oleracea

2. Ervas eretas

3. Lâmina foliar linear, séssil; fruto estipitado; sementes negras, tuberculadas......... P. elatior

3. Lâmina foliar espatulada, peciolada; fruto séssil; sementes acinzentadas a negras, lisas.......................................... P. mucronata

Portulaca elatior Mart. ex Rohrb., in Mart (ed.), Fl. bras. 14(2): 302. t. 69. 1872.

Figuras 1: C; 2: A

Ervas suculentas, $10-50 \mathrm{~cm}$ alt.; caule ereto, ramificado na base ou na região mediana. Folhas sésseis; lâmina linear, achatada ou cilíndrica, ápice obtuso a agudo, margem lisa, base aguda a obtusa, glabra a ligeiramente indumentadas; axilas nodais com tricomas amarelo-leitoso abundantes. Inflorescência corimbiforme, flores-3, sem brácteas. Flores de cálice glabro; corola amarela ou esbranquiçada, pétalas obovadas; estames 10-15; estigmas 5-7; ovário ínfero. Fruto pixídio, levemente estipitado; sementes tuberculadas, negras.

Material examinado: BRASIL. SERGIPE: Canindé do São Francisco, Fazenda Brejo, 0943'30,6”'S, 37059'03"'W, Silva et al. 09, 30/IX/1999, fr. (PEUFR); Fazenda Jaburu, Silva et al. 1064, 21/IX/1999, fl. e fr. (PEUFR); Idem, Silva \& Moura 1231, 10/XI/1999, fl. e fr. (PEUFR); Fazenda Xingozinho, 09³3'00”S, 3801'10"'W, Moura \& Silva 1175, 23/V/2000, fl. e fr. (PEUFR); Fazenda Canindé, Moura \& Silva 628, 20/ VIII/1999, fl. e fr. (PEUFR); Margem de Rio, Sales \& Moura 717, 08/VI/1999, fl. (PEUFR); Canyon, Moura 
\& Silva 683, 06/IX/1999, fl. e fr. (PEUFR); Fazenda Poço Verde, Silva \& Moura 1435, 28/III/2000, fl. e fr. (PEUFR); Fazenda Cana Brava, Melo et al. 258, 05/V/2000, fl. e fr. (PEUFR).

Distribuição geográfica: Ocorre em quase todo o Brasil, com exceção apenas para a região Sul (COELHO, 2012).

Portulaca elatior pode ser reconhecida facilmente no campo pelo hábito ereto, podendo apresentar indivíduos acima de 20cm compr. (LIMA; LIMA, 1968; COELHO; GIULIETTI, 2006; 2010; COELHO, 2009). Outro importante caráter é a presença de lâmina foliar linear que a distingue prontamente das demais espécies dessa família registradas para o Brasil (COELHO; GIULIETTI, 2010).

Portulaca halimoides L., Sp. pl. 2: 639. 1762.

Figura 1: D

Ervas prostradas, suculentas, ramificadas desde a base, axilas nodais densamente lanosas, tricomas esbranquiçados; ramos 5-20cm compr., pardos. Folhas pecioladas; lâmina linear a oblonga, cilíndrica, carnosa, ápice obtuso a arredondado, margem inteira, base arredondada; folhas involucrais 4-8 circundando a inflorescência, lineares a oblongas, glabras, semelhantes às demais folhas; base arredondada; ápice obtuso a arredondado, margem inteira. Inflorescência corimbiforme, 2-6 flores, sem brácteas. Flores glabras, de dorso côncavo; pétalas 4-5, brancas, lâmina obcordada, ápice emarginado; estames 6-12; estigmas 3-5; ovário ínfero. Fruto pixídio, estipitado, opérculo cônico; sementes negras, opacas, tuberculadas, com brilho metálico.

Material examinado: BRASIL. ALAGOAS: Canyon, Silva \& Moura 662, 27/VII/1999, fl. e fr. (PEUFR); Piranhas, Fazenda Baixa Verde, Silva \& Moura 1014, fl. e fr. (PEUFR). SERGIPE: Curituba. Prainha, Silva \& Moura 556, 16/VI/1999, fl. e fr. (PEUFR); Fazenda Jaburu, Moura \& Silva 747, 21/ IX/1999, fl. e fr. (PEUFR); Idem, Silva \& Moura 1231, 10/XI/1999, fl. e fr. (PEUFR); Fazenda Poço Verde, Moura \& Silva 1117, 28/III/2000, fl. e fr. (PEUFR); Idem, Moura \& Silva 1189, 25/V/2000, fl. (PEUFR).
FIGURA 2: A-D: Hábito de espécies de Portulacaceae s.l. da área de estudo. A. Portulaca elatior. B. Portulaca halimoides. C. Talinum paniculatum. D. Talinum triangulare.

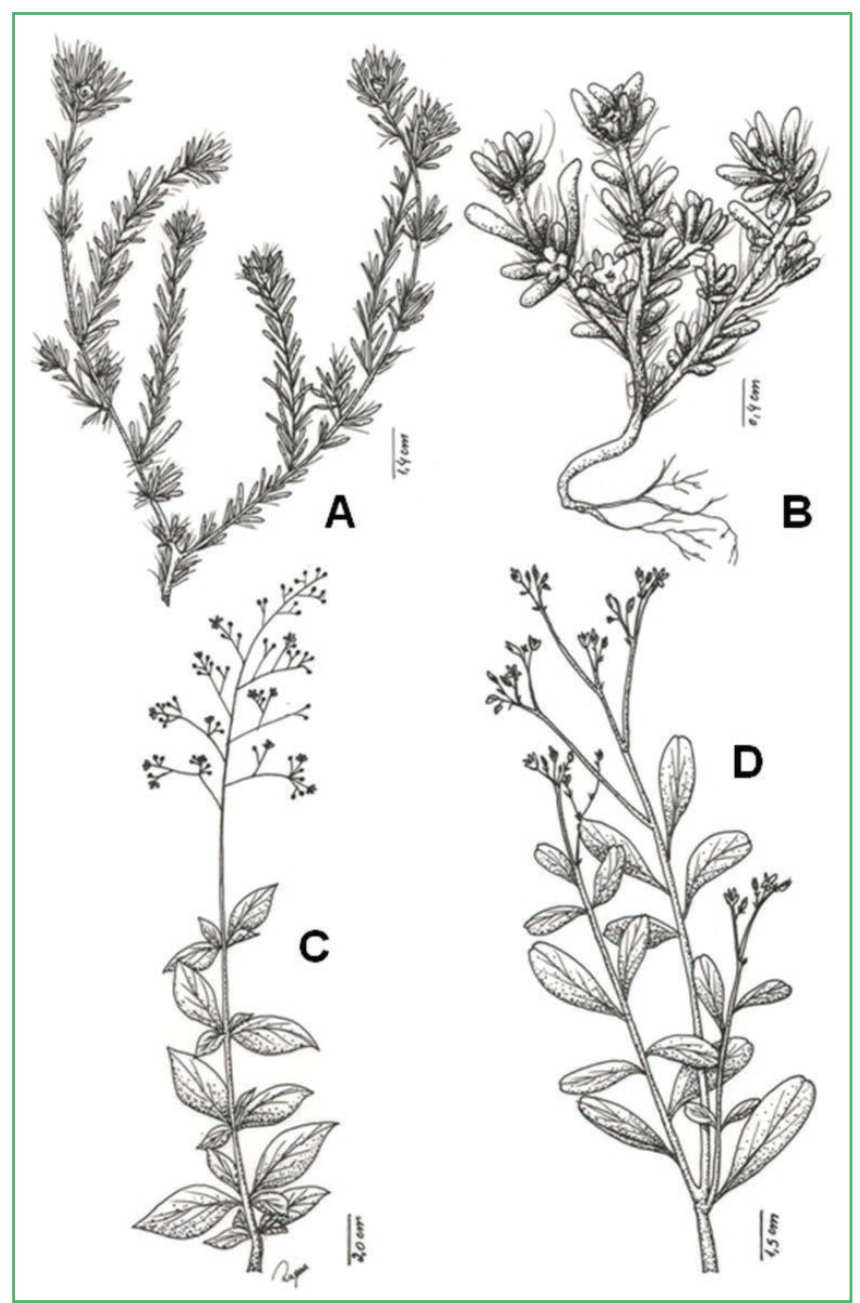

Distribuição geográfica: Equador, Venezuela (MOBOT, 2003) e no Brasil, onde ocorre em quase todo o país com exceção para a região Sul (COELHO, 2012).

A espécie é diferenciada das demais pela presença de estípite bem desenvolvido no fruto (LIMA; LIMA, 1968). Segundo Coelho e Giulietti (2006), a cor da corola não é uma característica que a delimita, por apresentar variações que vão do branco, amarelo ao rosa.

Portulaca mucronata Link, Enum. Hort. Berol. 2. 1822 .

Ervas 10-25cm alt.; caule ereto, ramificado desde a base; raízes espessadas. Folhas pecioladas; lâmina 
espatulada, plana, ápice agudo a acuminado, margem inteira, base arredondada, glabra; folhas involucrais 4-8 circundando a inflorescência; tricomas axilares. Inflorescência corimbiforme, 2-5 flores, sem brácteas. Flores amarelas; sépalas glabras, obovadas; pétalas obovadas; estames 10-30; estigmas 5-7; ovário ínfero. Fruto pixídio, séssil; sementes formadas por células esteluladas, cor cinza metálico tendendo a negras, lisas.

Material examinado: BRASIL. SERGIPE: Canindé do São Francisco, Fazenda Nova Arara, Andrade et al. 42, 21/VI/1998, fl. e fr. (PEUFR); Fazenda Jaburu, Moura \& Silva 838, 19/X/1999, fl. e fr. (PEUFR).

Distribuição geográfica: Bolívia, Paraguai (MOBOT, 2003) e em todas as regiões do Brasil (COELHO, 2012).

Em P. mucronata os ápices das folhas são agudos a acuminados, as flores são amarelas e as sementes sem ornamentação apresentam cor cinza metálico, além de seu hábito ereto (COELHO; GIULIETTI, 2006).

Portulaca oleracea L., Sp. pl.: 445. 1753.

Ervas 10-30 (40) cm, semiprostradas ou ascendentes, caules róseos, suculentas, glabras, muito ramificadas na base; raiz principal avermelhada. Folhas pecioladas, alternas ou semiopostas; lâmina geralmente espatulada às vezes ovada, plana, ápice arredondado, margem inteira, base arredondada, glabra; estípulas membranáceas. Inflorescência corimbiforme, terminal, congesta ou com flores solitárias; brácteas membranáceas. Flores amarelas, sésseis; sépalas com lóbulos largos, obtusos, dorso carenado; pétalas amarelas, obovadas; estames 8-15; estigmas-3; ovário ínfero. Fruto pixídio 4-8mm diâm., globoso, esverdeado, membranáceo, deiscente transversalmente, corola persistente; sementes reniformes, castanho-avermelhado escuro ou de cinzaescuro a negras.

Material examinado: BRASIL. ALAGOAS: Piranhas, Silva 700, 27/VII/1999, fr. (PEUFR). SERGIPE: Canindé do São Francisco, Fazenda Brejo, 0943'30,6”S, 3759'03' "W (PEUFR), Sales \& Moura 717, 08/VI/1999, fl. (PEUFR); Sales \& Moura 747, 08/VIII/1999, fl. e fr. (PEUFR); Silva et al. 09, 30/ IX/1999, fr. (PEUFR); Silva \& Moura 443, 03/XI/1999, fr. (PEUFR).
Distribuição geográfica: Ocorre nos Estados Unidos da América, México, El Salvador, Honduras, Guatemala, Nicarágua, Costa Rica, Caribe, Panamá, Venezuela, Colômbia, Peru, Equador, Chile, Madagascar, Camarões, República da África Central, Tanzânia e Zâmbia (MOBOT, 2003) e em todo o Brasil (COELHO, 2012), sendo encontrada em ambientes antropizados (LORENZI, 2008).

Pode ser reconhecível, principalmente, por apresentar caules róseos portando folhas de lâmina geralmente espatulada e pelas flores amarelas. Ilustrações podem ser encontradas em Coelho e Giulietti (2006, p. 184; 2010, p. 659).

Chave de identificação para as espécies de Talinum de Xingó (Alagoas e Sergipe):

1. Pedúnculo da inflorescência cilíndrico; estames 1015 ; sementes verrucosas. T. paniculatum

1. Pedúnculo da inflorescência triangular; estames 2040; sementes tuberculadas. T. triangulare

Talinum paniculatum (Jacq.) Gaertn., Fruct. Sem. P1. 2: 219. t.128. 1791.

Figuras 1: E; 2: C

Ervas suculentas, eretas, $10-60 \mathrm{~cm}$ alt., glabras, simples ou pouco ramificadas. Folhas pecioladas, alternas ou subopostas, mais adensadas na região basal caulinar; lâmina obovada ou oblanceolada, ápice agudo a arredondado, margem levemente denteada, base cuneada, glabra. Inflorescência paniculiforme, pedunculada; pedúnculo cilíndrico. Flores róseas ou brancas; sépalas decíduas, obovadas; estames 10-15; estiletes 1-2mm compr.; ovário súpero. Fruto cápsula globosa, amarela, valvar, cartácea; sementes verrucosas, marrom-escuras a negras.

Material examinado: BRASIL. SERGIPE: Canindé do São Francisco, Fazenda Brejo, Silva \& Moura 433, 02/VI/1999, fl. e fr. (PEUFR); Moura \& Silva 1171, 19/V/2000, est. (PEUFR); Fazenda Lagoa do Frio, Silva et al. 1248, 11/XI/1999, fl. e fr. (PEUFR); Fazenda Jaburu, Moura \& Silva 744, 21/IX/1999, fl. e fr. (PEUFR); Fazenda Olho d'Água do Casado, Moura \& Silva 763, 23/IX/1999, fl. e fr. (PEUFR); Fazenda Cana Brava, Moura \& Silva 1142, 05/V/2000, fl. e fr. (PEUFR). 
Distribuição geográfica: Ocorre em, praticamente, todo o Brasil, nas regiões Nordeste, Centro-Oeste, Sudeste e Sul (COELHO, 2012).

Segundo Coelho e Giulietti (2006), T. paniculatum é facilmente reconhecível devido ao pedúnculo cilíndrico da inflorescência, sendo distinta de $T$. triangulare, que apresenta inflorescência de pedúnculo triangular.

Talinum triangulare (Jacq.) Willd., Sp. pl. 2: 862. 1800 .

Figuras 1: F; 2: C

Ervas suculentas, eretas, $15-60 \mathrm{~cm}$ alt., glabras, ramificadas. Folhas alternas ou subopostas, pecioladas; lâmina obovada, ápice emarginado, margem inteira, base cuneada, glabra. Inflorescência cimeira monocasial, pedunculada; pedúnculo triangular. Flores róseas; sépalas sésseis, obovadas; estames 20-40; estiletes 1-2 mm compr., ovário súpero. Fruto cápsula globosa, amarela, com pontos avermelhados, valvar; sementes tuberculadas, superfície levemente estriada, marrom-escuras a negras.

Material examinado: BRASIL. SERGIPE: Canindé do São Francisco, Fazenda Brejo, Moura \& Silva 331, 03/VI/1999, fl. (PEUFR); Fazenda Poço Verde, Moura \& Silva 1130, 13/IV/2000, fl. e fr. (PEUFR); Fazenda Cana Brava, Melo et al. 262, 05/V/2000, fl. e fr. (PEUFR).

Distribuição geográfica: No Brasil, a espécie ocorre nas regiões Norte, Nordeste, Centro-Oeste e Sul (COELHO, 2012). Caracteriza-se, especialmente, pelos pedúnculos da inflorescência triangulares, sépalas sésseis e por apresentar 20-40 estames. Segundo Lorenzi (2008), apresenta importância econômica sendo utilizada para alimentação humana.

\section{Referências}

COELHO, A. A. O. P. Portulacaceae. In: ALVES, M.; ARAÚJO, M. F.; MACIEL, J. R.; MARTINS, S. (Ed.). Flora de Mirandiba. Recife: Associação Plantas do Nordeste, 2009. p. 312-316.

COELHO, A. A. O. P. Portulacaceae. In: FORZZA, R. C.; FILARDI, F. L. R.; COSTA, A.; CARVALHO-JÚNIOR, A. A.; PEIXOTO, A. L.; WALTER, B. M. T.; BICUDO, C.; MOURA, C. W. N.; ZAPPI, D.; COSTA, D. P.; LLERAS, E.; MARTINELLI, G.; LIMA, H. C.; PRADO, J.; STEHMANN, J. R.; BAUMGRATZ, J. F. A.; PIRANI, J. R.; SYLVESTRE, L. S.; MAIA, L. C.; LOHMANN, L. G.; PAGANUCCI, L.; SILVEIRA, M.; NADRUZ, M.; MAMEDE, M.
M. M.; BASNTOS, M. N. C.; MORIN, M. P.; BARBOSA, M. R.; MENEZES, M.; HOPKINS, M.; SECCO, R.; CAVALCANTI, T.; SOUZA, V. C. (Org.). Lista de espécies da flora do Brasil. 2012. Disponível em: <http://floradobrasil.jbrj.gov.br/2012/FB020630>. Acesso em: 27 jan. 2012.

COElHO, A. A. O. P.; GIUlietTI, A. M. Flora da Bahia: Portulacaceae. Sitientibus - Série Ciências Biológicas, Feira de Santana, v. 6, n. 3, p. 182-193, 2006.

COELHO, A. A. O. P.; GIUlietTI, A. M. O gênero Portulaca L. (Portulacaceae) no Brasil. Acta Botanica Brasilica, Feira de Santana, v. 24, n. 3, p. 655-670, 2010.

JUDD, W. S.; CAMPBELL, C. S.; KELLOGG, E. A.; STEVENS, P. F.; DONOGHUE, M. J. Sistemática vegetal: um enfoque filogenético. 3. ed. Porto Alegre: Artmed, 2009. 632 p.

LIMA, D. A.; LIMA, A. M. B. Flora de Pernambuco: Portulacaceae. In: CONGRESSO NACIONAL DE BOTÂNICA, 19, 1968, Fortaleza. Anais... Fortaleza: SBB, 1968. p. 60-63.

LORENZI, H. Plantas daninhas do Brasil. 4 ed. São Paulo: Instituto Plantarum, 2008. 608 p.

KÖEPPEN, W. Climatologia. México: Ed. Fondo de Cultura Ecónomica, 1948. 496 p.

MOBOT - MISSOURI BOTANICAL GARDEN. 2003. W Tropicos. Disponível em: <http://www.mobot.org/w3 search/vast. html>. Acesso em: 27 jan. 2012.

NYANANYO, B. L.; MENSSAH, S. I. Distribution and origins of members of the Family Portulacaceae (Centrospermae). Journal of Applied Science and Environmental, Port Harcourt, v. 8, n. 2, p. 59-62, 2004.

NYFFELER, R.; EGGLI, U. An up-to-date familial and suprafamilial classification of succulent plants. Bradleya, Winterthurerst, v. 28 , p. $125-144,2010$.

RADAMBRASIL. Levantamento de recursos naturais: Aracaju. Recife. Rio de Janeiro: RADAMBRASIL, 1983. Folhas: SC. 23 e SC. 24.

RODRIGUES, M. I. A.; FURLAN, A. Portulacaceae. In: WANDERLEY, M. G. L.; SHEPBEAL, G. J.; GIULIETTI, A M. (Ed.). Flora fanerogâmica do estado de São Paulo. v. 2. São Paulo: Hucitec, 2002. p. 261-268.

VELOSO, H. P.; RANGEL-FILHO, A. L. R.; LIMA, J. C. A. Classificação da vegetação brasileira: adaptada a um sistema universal. Rio de Janeiro: Instituto Brasileiro de Geografia e Estatística, 1992. 123 p. 